\title{
Government R\&D Investment, Knowledge Accumulation, and Regional Innovation Capability: Evidence of a Threshold Effect Model from China
}

\author{
Chen Gong \\ College of Economics and Management, Qiqihar University, Qiqihar, Heilongjiang 161006, China \\ Correspondence should be addressed to Chen Gong; gongchen@qqhru.edu.cn
}

Received 22 June 2021; Accepted 17 September 2021; Published 28 September 2021

Academic Editor: Zaoli Yang

Copyright ( 2021 Chen Gong. This is an open access article distributed under the Creative Commons Attribution License, which permits unrestricted use, distribution, and reproduction in any medium, provided the original work is properly cited.

\begin{abstract}
Innovation is the primary driving force of development and the strategic support for building a modern economic system. For enterprises, continuous innovation capabilities can effectively deal with uncertainties in the business environment and can enhance business competitiveness. Macropolicies can stimulate economic development and can try to promote enterprise innovation, but there is still widespread debate in academia about whether these policies successfully promote or, in fact, inhibit innovation. Looking at the provincial panel data from China between 2009 and 2018, the authors of this paper explored the complex nonlinear mechanism of government R\&D investment in driving regional innovation capabilities from the perspective of knowledge accumulation. The empirical results show that, when the level of knowledge accumulation is used as the threshold variable, there is an obvious threshold effect between government R\&D input and regional innovation capabilities. As the level of knowledge accumulation crosses the threshold, the influence of government R\&D investment on regional innovation capabilities undergoes a structural mutation, shifting from an insignificant inhibitory effect to a significant promotional effect. The above conclusion has strong robustness. This article provides useful policy enlightenment for China to promote the development of scientific and technological civilization and the construction of an innovative country.
\end{abstract}

\section{Introduction}

China has achieved "remarkable growth in global economy" with its demographic dividend and factor investment since the reform and opening-up, with the gross domestic product (GDP) exceeding CNY 100 trillion in 2020 [1]. On the whole, however, China's economic growth is characterized by "high quantity, low quality, and low efficiency" and faces structural problems, such as the depletion of demographic dividends and cost advantage, resource constraints, environmental pollution, and the significant slowdown of the economic growth rate [2]. Economic development has entered the "new normal" stage, in which the extensive economic growth mode driven by factor input urgently needs to be transformed, and the specific way to promote healthy and sustainable economic development lies in improving regional innovation capability $[3,4]$. As a result, strategic policies such as "innovation is the first driving force to lead development" and "innovation drives development" point out that innovation has become an important measure for enhancing China's comprehensive national strength and a key step for China's economy in moving towards highquality development. For a long time, technological innovation has been a competitive field for enterprises in developed countries. In recent years, the global technological landscape has begun to change. Some late-developing countries that predominantly relied on Western technology in the past have gradually become new and important players in the field of international technological innovation. Silicon Valley, in the United States, produces dozens of technological achievements, on average, every day. These achievements have promoted the development of science and technology in the world. It is the largest technological innovation area in the world. The small town has rapidly 
developed into a city of millions of people and has promoted the development of the entire Indian software industry. It is a model of the developing world becoming reliant upon high technology.

Technological innovation is a high-input, high-risk innovation activity [5] because, for enterprises, large-scale costs are needed at the beginning of innovation activities, which are supported by local governments. This is especially true for a large country with significant regional heterogeneity, such as China, where innovation activities vary greatly from region to region. Moreover, in the Outline of the National Medium and Long-Term Science and Technology Development Plan (2006-2020), it is proposed that the government should take the lead in the process of building the national innovation system. In the Outline of the Thirteenth Five-Year Plan for National Economic and Social Development of the People's Republic of China, it is proposed to strengthen the government's innovation support policy. Thus, it is clear that local government, as an important subject participating in the construction of a regional innovation system, plays a significant guiding role in improving regional innovation capability $[6,7]$.

Government R\&D investments have an impact on the promotion of regional innovation capability, which is reflected in two main aspects. First, government financial support can effectively compensate for the "innovation inertia" of enterprises, alleviating the innovation risk of microinnovation subjects, reducing the uncertainty of innovation activities, and helping to stimulate the innovation power of enterprises [8], as the construction of a regional innovation system is a systematic project that involves many factors. A regional innovation system also signifies the direction of the regional economic development to the market, which is conducive to producing demonstration effects and guiding regional enterprises to carry out innovation activities [9]. Secondly, although government innovation support is conducive to enterprise innovation activities, the serious information asymmetry between the government and market players can easily lead to the distortion of innovation incentives, such as the mismatch of resources caused by enterprises defrauding government innovation subsidies, or the "innovation illusion" and "patent bubble" formed by the enterprise engaging in low-quality innovation activities with the subsidy $[10,11]$, and the neglected innovation quality caused by the "economic and political human" devoting him or herself to the number of innovations in the pursuit of short-term achievements [11]. Based on the above summary of the theoretical connotation of the relationship between government R\&D investments and regional innovation capability, the authors of this paper believe that $\mathrm{R} \& \mathrm{D}$ investments have uncertain impacts on regional innovation capability.

Therefore, the aim of this study was to answer the following three questions: What is the level of knowledge accumulation in each region in China, and are there significant differences? What is the role of government $\mathrm{R} \& \mathrm{D}$ investments in regional innovation capability? Is there a nonlinear relationship between government R\&D investment and regional innovation capability considering the level of knowledge accumulation? Thus, our goal was to reveal the relationship between government R\&D investment, knowledge accumulation, and regional innovation capability.

\section{Literature Review}

Innovation is an important driving force for development and the strategic support for building a modern economic system. It is necessary to strengthen the construction of a national innovation system and strengthen strategic scientific and technological forces. However, the implementation of policies may lead to government failures, and government failures are more serious than market failures. At the same time, the relationship between the enterprise and the environment on which the policy is based also affects the overall effectiveness of the innovation policy. Therefore, improving government innovation support, deepening knowledge accumulation, improving enterprise innovation performance, and strengthening innovation-driven development have all become important development strategies for all countries [12]. Consequently, increasing attention has been paid to regional innovation capability in academic circles [13-17], and the issue of whether government $R \& D$ can effectively promote the enhancement of regional innovation capability has been studied.

Some scholars believe that government R\&D investments can promote regional innovation capability. For example, Blanes and Busom analyzed the innovationdriven effect of government subsidies from the theoretical level based on the Solow economic growth model. They believed that government innovation subsidies effectively alleviated the risks faced by enterprises in technological innovation activities and could increase the innovation motivation of microsubjects, improving their innovation enthusiasm and promoting the improvement of regional innovation capability [18]. Neicu et al. proposed that government $\mathrm{R} \& \mathrm{D}$ subsidies significantly improved the innovation performance of enterprises based on a data test of French SMEs [19]. Similarly, Cin et al. also confirmed the positive correlation between government $\mathrm{R} \& \mathrm{D}$ subsidies and innovation performance based on an empirical analysis of Korean SMEs [20]. Xu et al., based on a panel data analysis in China, analyzed the impact of government direct subsidies and indirect tax reduction and innovation support on innovation performance by studying small- and medium-sized enterprises in 30 regions and analyzed the mediating and regulating role of intellectual property protection in its influence process [21]. Zhang and Huang studied 274 cities in China and concluded that government innovation support has a steady role in promoting regional innovation capability, but its impact is significantly different under different levels of heterogeneity [8]. Chen empirically studied the data of microenterprises in China and proposed that government innovation support is beneficial for compensating for market failures, especially with mismatches in enterprise innovation resources, which is conducive to promoting enterprise innovation performance [12]. 
Other scholars have pointed out that government R\&D investments will have a "crowding-out effect" on enterprises' innovation investments, resulting in a mismatch in innovation resources, which will further inhibit regional innovation capability. For example, Lach studied the relationship between the Israeli Government's R\&D subsidy and innovation performance and believed that the government's R\&D investment would guide enterprises to invest heavily in government-supported innovation fields through leverage, which hindered the innovation progress within the region as a whole and then inhibited the improvement of regional innovation capability [22]. Boeing performed an empirical test on Chinese enterprises and pointed out that most of the Chinese government's innovation subsidies are distributed to state-owned enterprises, and fewer to private enterprises, with a certain "crowding-out effect" on enterprises' innovation investments [23].

Scholars have reached different conclusions in the research on the relationship between government R\&D investment and regional innovation capability, which may be due to the fact that the related research based on enterprise microdata ignores the government's innovation expectation at the macro-level [8] and that the innovation driving effect of government R\&D investment may be different considering the significant heterogeneity of knowledge accumulation levels in different regions because innovation is a high-knowledge-intensive system that is engineered with typical characteristics of knowledge accumulation [24].

The existing literature has provided rich and profound insights, but on the whole, it presents two aspects to consider. One is that using the provinces as the basic research unit to represent the government's innovation support from the perspective of the government's R\&D investment and incorporating the government's $\mathrm{R} \& \mathrm{D}$ investment into the analysis framework of the influencing factors of regional innovation capability is beneficial for making policy adjustments for the Chinese regional governments from the perspective of expenditure allocation and further promoting the leap of regional innovation capability. The second is that putting government R\&D investment, knowledge accumulation, and regional innovation capability within the same framework to explore whether there is a nonlinear relationship among them can provide targeted policy inspiration and theoretical support for different regional governments to carry out innovation support activities.

\section{Methodology}

3.1. Threshold Model. Considering the significant difference in the level of knowledge accumulation among different regions in China [25], government $R \& D$ investments may have a threshold effect on the promotion of regional innovation capability, which requires the interval division of the level of knowledge accumulation based on a certain threshold value in order to accurately identify the factors that influence the direction and magnitude of the government R\&D investment on regional innovation capability. In order to avoid the randomness effect of artificial grouping, the nonlinear panel threshold model proposed by Hansen is selected in this paper [26,27], which can accurately identify the data characteristics of unknown variables and scientifically group them and then test the significance of endogenous threshold effect. According to the variables selected in this paper, the threshold model was constructed as follows.

The threshold model of government R\&D investment in regional innovation capability can be expressed by the following equation:

$$
\mathrm{RIC}_{i t}=\theta+\alpha_{1} \mathrm{Human}_{i t}+\alpha_{2} \mathrm{City}_{i t}+\alpha_{3} \mathrm{IND}_{i t}+\alpha_{4} \mathrm{MES}_{i t}+\beta_{1} R \& D_{i t} I\left(\mathrm{KNO}_{i t} \leq \eta\right)+\beta_{2} \mathrm{R}_{i t} \mathrm{I}\left(\mathrm{KNO}_{i t}>\eta\right)+u_{i}+\varepsilon_{i t}
$$

where $i=$ the province and $t=$ the year; the control variables include Human $_{i t}=$ the human capital; City $_{i t}=$ the city level of the region; $\mathrm{IND}_{i t}=$ the industrial structure; and $\mathrm{MES}_{i t}=$ the level of informatization.

Key variables include $\mathrm{RIC}_{i t}=$ the regional innovation capability; $\mathrm{R} \& \mathrm{D}_{i t}=$ the level of government $\mathrm{R} \& \mathrm{D}$ investment; $\mathrm{KNO}_{i t}=$ the level of knowledge accumulation of the region; $\eta=$ the threshold value; $I(\bullet)=$ the indicative function; $u_{i}=$ the specific effect of individuals; and $\varepsilon_{i t}=$ the stochastic disturbance terms.

In addition, the multithreshold panel model is analogized and will not be described here.

To test the nonlinear panel threshold model, the average value in the group was subtracted from each observed value to eliminate the individual effect, and then the dispersion form of the model was obtained and the threshold and parameters were jointly estimated. On this basis, it was necessary to test the rationality of the use of the threshold model from two aspects. One was to test the existence of the threshold effect. With the null hypothesis of $H_{0}: \eta_{1}=\eta_{2}$, the significance test of the $P$-value was carried out by the "bootstrap sampling method." The second was to test the authenticity of the threshold estimate by using the single threshold test as an example. With the null hypothesis of $H_{0}: \eta_{1}=\eta_{2}$, and the likelihood ratio statistic is the LR obeying the nonstandard normal distribution, the threshold estimate test was performed according to Hansen's formula for calculating rejection region, that is, under the condition of significance level $\tau$, the null hypothesis is rejected when LR $>-2 \ln (1-\sqrt{1-\tau})$. The multiple-threshold test can be performed similarly.

\subsection{Variable Description and Data Processing}

(1) Explained variable: regional innovation capability (RIC). The ultimate goal of regional enterprise innovation activities is to achieve more considerable economic benefits, while the sales revenue of new 
products reflects the market acceptance of regional innovative products, which fundamentally reflects the market value of innovative activities and innovative technologies [28]. Thus, in this study, with reference to the research by Su et al. [29, 30], the regional innovation capability was characterized by the sales revenue of new products that represent the final output of the regional innovation system.

(2) Explanatory variable: government R\&D subsidy $(R \& D)$. As the basic way for a government to participate in the construction of a regional innovation system, as an important aspect of a regional innovation system is financial expenditure, the government's preference can be reflected by adjusting the proportion of government expenditure allocation. Regional governments can effectively guide and support regional R\&D activities by investing in science and technology [31]. Thus, in this study, referring to the research by Zhang and Huang [8], the government R\&D subsidy level was calculated by using the proportion of local science and technology input to financial expenditure.

(3) Threshold variable: knowledge accumulation (KNO). In order to explore the heterogeneous effect of different levels of knowledge accumulation on government $\mathrm{R} \& \mathrm{D}$ subsidy-driven regional innovation capability enhancement, in this study, drawing on the research of Chen et al. [25], the amount of patent authorization was used to characterize the regional level of knowledge accumulation. In addition, the regional level of knowledge accumulation was characterized in this study using the patent authorization volume since it represents the regional level of the accumulation of technical information.

Drawing on previous studies, in this study, some variables, such as human capital, urbanization level, industrial structure, and level of informatization, were also controlled.

(4) Human capital (Human): as an essential element of innovation development, high levels of human capital accumulation can both increase the level of labor productivity and effectively raise the sense of innovation among the regional populace, which in turn has an impact on the region's innovation activities and innovation ability. Drawing on the crosscountry comparative series study on educational attainment conducted by Barro and Lee [32], combined with the setting of years of education in China, the level of human capital accumulation is characterized by the average level of education. where Human indicates the human capital of a region, and primary, junior, senior, and college, respectively, indicate the proportion of people over 6 years of age with elementary, junior, high school, university, or higher education.

(5) City level (City): the process of urbanization is accompanied by the agglomeration of population and elements, which has an uncertain impact on regional innovation capability. On the one hand, the advancement of urbanization promotes the accumulation of a large amount of capital, labor, and other factors, which is conducive to the optimization of resource allocation and knowledge spillover and promotes the technological progress and technological accumulation, which can promote the improvement of regional innovation capability. On the other hand, the agglomeration of factors brought by urbanization may also have a congestion effect, which hinders the improvement of enterprise innovation performance [33]. Thus, in this study, referring to the research of Komlosi et al. [34], the proportion of the urban resident population out of the total population was used to characterize the city level of the region.

(6) Industrial structure (IND): the main task for China to deepen the structural reform on the supply side is to promote the transformation from the extensive growth mode driven by factor inputs to the intensive economic growth model driven by technological innovation. Therefore, the rational transformation and upgrading of the industrial structure will contribute to the rational allocation of factor resources and promote the transfer of R\&D investments, human capital, and other factors to the tertiary industry characterized as knowledge-intensive and technology-intensive, thus contributing to the promotion of technological innovation capability [35]. Thus, in this study, referring to the research of Li et al. [36], the ratio of the output value of the tertiary industry to that of the secondary industry was used to characterize the industrial structure.

(7) Level of informatization (MES): with the innovation and development of cloud computing and intelligent manufacturing, the data economy model has become an important part of the market economy. In addition, information technology can accelerate the integration and penetration between industries, promote the development and growth of producer services, spawn the emergence and growth of new service formats, promote the development of hightech industries and strategic emerging industries, and change the proportion structure among industrial departments. At the same time, the biased technological progress brought by the application of 
information technology can change the marginal substitution rate of energy and other factors, change the relative input of resource factors, and improve the efficiency of resource allocation and innovation level. Thus, in this paper, referring to the research of Liu and $\mathrm{Hu}$ [37], the level of informatization is represented by the post and telecommunications business volume.

The data used in this study are from the China Statistical Yearbook, the China Science and Technology Statistical Yearbook, the China Population and Employment Statistical Yearbook, and regional statistical yearbooks. To control the estimation error and heteroscedasticity, the related variables involved in this study were processed by a logarithm and corresponding reduction. Table 1 shows the correlation matrix and descriptive statistics of the variables. The test results show that most of the variables are correlated at a $1 \%$ significance level, the correlation coefficient between the core variables is small, and the direction of action is basically consistent with the above analysis in this paper. For example, the correlation coefficient between the government R\&D subsidy and the enhancement of regional innovation capability is 0.6008 at a $1 \%$ significance level, indicating that the government $\mathrm{R} \& \mathrm{D}$ subsidy is helpful to stimulating regional innovation vitality and enhancing regional innovation capability.

\section{Results and Discussion}

4.1. Result Analysis. Based on the panel threshold measurement method, an empirical exploration of the complex mechanisms between government R\&D investments and regional innovation capability was conducted under the condition of the level of knowledge accumulation in various regions. First of all, the $\mathrm{F}$ value and the corresponding selfsampling $P$-value, as well as the critical values at the $1 \%, 5 \%$, and $10 \%$ significance levels were obtained using knowledge accumulation as the threshold variable after the threshold effect test, as shown in Tables 2 and 3. Based on Hansen's threshold theory, the single threshold effect of the model passes the test; that is, there is a significant threshold effect of knowledge accumulation with a threshold value of 6.4457 . On these grounds, the threshold effect was analyzed in detail.

After testing the threshold effect, the estimated results of the threshold value, that is, the $95 \%$ confidence interval of the threshold value, can be clearly seen when knowledge accumulation is taken as the threshold variable with the help of the likelihood ratio function graph. In the threshold model used in this study, the estimated threshold value is 6.4457, as shown in Figure 1, and the likelihood ratio statistic value is zero. The $95 \%$ confidence interval of the threshold estimate is an interval composed of all critical values (dashed lines in the corresponding graph), with LR values less than $5 \%$, which passes the authenticity test of the threshold estimate. Therefore, it is possible to divide the provinces of China into two types of knowledge accumulation-low $(\mathrm{KNO} \leq 6.4457)$ and high $(\mathrm{KNO}>6.4457)$-based on the two threshold values.
The threshold regression results indicate that the driving effect of government R\&D investment on regional innovation capability is not monotonically increasing (decreasing), and the coefficient of the driving effect of the government $\mathrm{R} \& \mathrm{D}$ investment varies significantly in different provinces; that is, as the level of knowledge accumulation continually jumps, it will first exert inhibition and then promotional effects on regional innovation capability. As shown in Table 4, when the level of knowledge accumulation is lower than 6.4457 , every $1 \%$ increase in a government R\&D investment will lead to a decrease in regional innovation capability by $27.3455 \%$, but it is not significant. When the level of knowledge accumulation exceeds the threshold value, that is, when the level of knowledge accumulation is higher than 6.4457, the direction of the government R\&D investment on regional innovation capability changes suddenly, the influence coefficient changes from a negative to a positive value, and the significance value changes from an insignificant value to a significant value. Every $1 \%$ increase of a government $\mathrm{R} \& \mathrm{D}$ investment will promote an increase in regional innovation capability by $16.9577 \%$, which shows that the interval of the high knowledge accumulation level $(\mathrm{KNO}>6.4457)$ is the best for knowledge accumulation.

With the continuous improvement of the threshold level of knowledge accumulation, the impact of government R\&D investments on regional innovation capability changes from insignificant inhibition to significant promotion, with a significant threshold effect. The role of government $\mathrm{R} \& \mathrm{D}$ investments in promoting regional innovation capability is constrained by the level of regional knowledge accumulation, which is reflected in the fact that the lower level of knowledge accumulation is not conducive to the innovation-driven effect of government $R \& D$ investments, while the higher level can improve the positive driving effect of government R\&D investments on regional innovation capability. Theoretically, it reflects that knowledge accumulation has a "critical scale" to drive the innovation of government R\&D investments because once knowledge accumulation breaks through the critical scale, that is, the higher the level of regional knowledge accumulation, the more effective the government $\mathrm{R} \& \mathrm{D}$ investment can guide enterprises to engage in innovation activities, and the more obvious the improvement of regional innovation capability is. On the one hand, the government's R\&D investment guides the endogenous support of knowledge accumulation in enterprise innovation. The support of knowledge accumulation in the areas of high-tech industry agglomeration, high-quality talent flow, and the integration of industry, university, and research is the internal foundation and necessary conditions for the emergence of innovation results, which runs through the whole process of innovation activities, and will improve the efficiency of knowledge search in technological frontier areas, guide enterprises to identify the technical problems and product positioning with the most market value, and promote enterprises to achieve the best innovation performance. At the same time, the accumulation of knowledge also means that enterprises have considerable intellectual property rights and independent property 
TABLE 1: Correlation matrix and summary statistics of variables.

\begin{tabular}{|c|c|c|c|c|c|c|c|}
\hline Variable & RIC & $\mathrm{R} \& \mathrm{D}$ & $\mathrm{KNO}$ & Human & City & IND & MES \\
\hline RIC & 1.000 & & & & & & \\
\hline $\mathrm{R} \& \mathrm{D}$ & $0.6088^{* * *}$ & 1.000 & & & & & \\
\hline KNO & $0.7185^{* * *}$ & $0.6456^{* * *}$ & 1.000 & & & & \\
\hline Human & $0.4293^{* * *}$ & $0.6473^{* * *}$ & $0.4349^{* * *}$ & 1.000 & & & \\
\hline City & $0.4876^{* * *}$ & $0.7914^{* * *}$ & $0.5082^{* * *}$ & $0.8655^{* * *}$ & 1.000 & & \\
\hline IND & $0.0443^{* * *}$ & $0.4942^{* * *}$ & $0.1757^{* * *}$ & $0.6639^{* * *}$ & $0.5639^{* * *}$ & 1.000 & \\
\hline MES & $0.7531^{* * *}$ & $0.4711^{* * *}$ & $0.8127^{* * *}$ & $0.2032^{* * *}$ & $0.2820^{* *}$ & $0.1271^{* * *}$ & 1.000 \\
\hline Sample size & 300 & 300 & 300 & 300 & 300 & 300 & 300 \\
\hline Mean & 16.6995 & 0.0199 & 9.7331 & 9.0107 & 0.5590 & 1.0814 & 6.4688 \\
\hline $\mathrm{SD}$ & 1.6026 & 0.0142 & 1.4894 & 0.9369 & 0.1285 & 0.6121 & 0.9185 \\
\hline Minimum & 11.3861 & 0.0039 & 5.5759 & 6.7639 & 0.2989 & 0.4996 & 3.8772 \\
\hline Maximum & 19.8402 & 0.0720 & 13.0775 & 12.6754 & 0.8960 & 4.3476 & 9.3069 \\
\hline
\end{tabular}

Notes: ${ }^{*}$ means $p \leq 0.05,{ }^{* *}$ means $p \leq 0.01$, and ${ }^{* * *}$ means $p \leq 0.001$.

TABle 2: Test results of the significance of the threshold effect of knowledge accumulation.

\begin{tabular}{ccccccc}
\hline & \multirow{2}{*}{$F$} & \multirow{2}{*}{ S } & \multicolumn{4}{c}{ Critical values } \\
& & & & $1 \%$ & $5 \%$ & $10 \%$ \\
\hline Threshold & $38.79^{* *}$ & 0.0133 & 300 & 38.8477 & 28.7641 & 25.7856 \\
\hline
\end{tabular}

Notes: ${ }^{*}$ means $p \leq 0.05,{ }^{* *}$ means $p \leq 0.01$, and ${ }^{* * *}$ means $p \leq 0.001$.

TABLE 3: Threshold value and confidence interval.

\begin{tabular}{lcc}
\hline Test & $\begin{array}{c}\text { Estimated threshold } \\
\text { value }\end{array}$ & $\begin{array}{c}95 \% \text { confidence } \\
\text { interval }\end{array}$ \\
\hline $\begin{array}{l}\text { Threshold } \\
\text { value }\end{array}$ & 6.4457 & {$[6.4281,6.5709]$} \\
\hline
\end{tabular}

rights, so they can obtain R\&D innovation income at a lower cost, promote their independent $\mathrm{R} \& \mathrm{D}$ progress, and improve the innovation ability within enterprises and regions as a whole. On the other hand, the high accumulation of knowledge in the process of promoting regional innovation capability by government $R \& D$ investments is helpful for government R\&D investments to digest, absorb, and transform external search knowledge, which can quickly transform cutting-edge technology obtained through foreign investment, technical cooperation, and knowledge exchange into capital that is actually owned by enterprises, and serve the process of production and operation activities of enterprises, so as to improve their innovation performance.

In terms of control variables, human capital has a significant positive impact on regional innovation capability, indicating that human capital is an important factor in promoting regional innovation capability and can provide necessary human support for innovation activities. Generally speaking, the improvement of innovation capability will inevitably involve the introduction of advanced technology and the improvement of original production processes, but the absorption and utilization of technology introduction is uncertain, which can be alleviated by certain human capital accumulation. In addition, the knowledge spillover effect caused by a large number of high-end human capital accumulation also contributes to the internal technology accumulation and promotes independent innovation. Urbanization has a positive impact on regional innovation capability at a significant level of $1 \%$, which indicates that urbanization has produced an agglomeration effect and promoted innovation development during the sample period. For example, Jiangsu, Shanghai, Guangzhou, and other eastern coastal areas with higher innovation levels are areas with higher urbanization levels in China because more high-quality talents are gathered in high-income cities, which can influence the economic behavior of the government and enterprises through knowledge exchange and talent gathering, greatly promoting the innovation capability within the region. It should be noted that although the industrial structure has a positive impact on the regional innovation capability, the effect coefficient is not significant, which is also consistent with the current development situation in China's economic transition period. Moreover, due to the lack of digestion and absorption capacity of China's high-knowledge-intensive enterprises and high-tech enterprises, and the lack of matching learning and transformation ability, they cannot effectively produce the knowledge spillover effect, and as a result, the innovation driving effect is not significant. In addition, the promotion of informatization has not been effectively verified.

4.2. Robustness Test. To test the robustness of the results, the robustness test method by Qi [38] was used as a reference to adjust the research sample in this paper to test for possible outlier errors in the results and verify the robustness above, by deleting the sample regions with the largest and smallest regional innovation capability index of about $1 \%, 5 \%$, and $10 \%$ in turn, and conducting three threshold model tests on 28 regions, 26 regions, and 24 regions in China, respectively. The influence coefficient and significance level of explanatory variables in the results are similar to the above test results, with no significant difference, indicating that the empirical results of this study are robust (because of the length limits, only the empirical results of 26 regions are listed here, as shown in Table 5). 


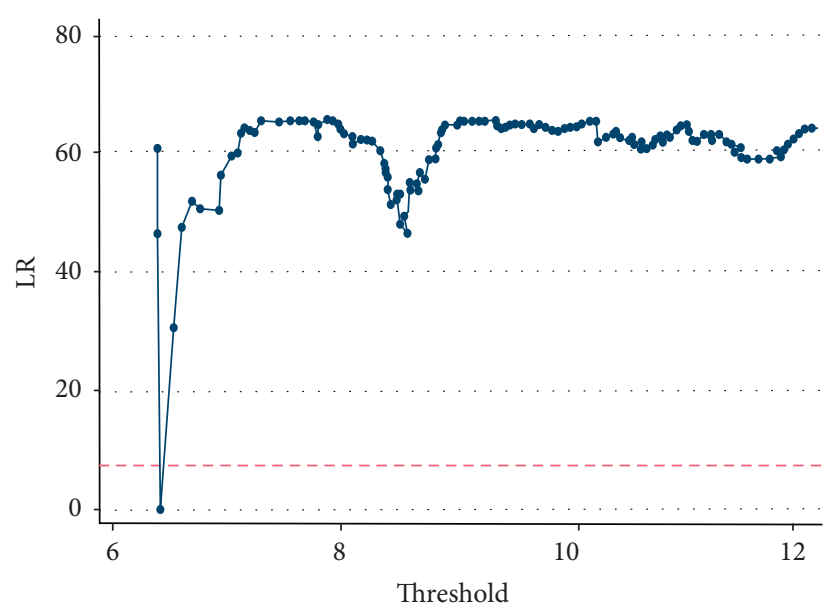

FIGURE 1: Estimated value and confidence interval of the knowledge accumulation threshold.

TABLE 4: Model parameter estimation results.

\begin{tabular}{lcccccc}
\hline RIC & Coef. & Std. err & $t$ & $p$ & $95 \%$ & Conf. interval \\
\hline Human & $0.2777^{* *}$ & 0.0899 & 3.09 & $\leq 0.01$ & 0.1006 & 0.4548 \\
City & $6.6614^{* * *}$ & 0.9578 & 6.95 & $\leq 0.001$ & 4.7755 & 8.5472 \\
IND & 0.0129 & 0.1188 & 0.11 & 0.914 & -0.2210 & 0.2468 \\
MES & -0.0346 & 0.0525 & -0.66 & 0.510 & -0.1380 & 0.0687 \\
R\&D $($ KNO $\leq 6.4457)$ & -27.3455 & 20.6312 & -1.33 & 0.186 & -67.9680 & 13.2771 \\
R\&D $($ KNO $>6.4457)$ & $16.9577^{* *}$ & 4.9118 & 3.45 & $\leq 0.01$ & 7.2863 & 26.6291 \\
Cons & $10.3542^{* * *}$ & 0.6585 & 15.72 & $\leq 0.001$ & 9.0576 & 11.6509 \\
\hline
\end{tabular}

Notes: ${ }^{*}$ means $p \leq 0.05,{ }^{* *}$ means $p \leq 0.01$, and ${ }^{* * *}$ means $p \leq 0.001$.

TABle 5: Robustness test estimate.

\begin{tabular}{|c|c|c|c|c|c|c|}
\hline RIC & Coef. & Std. err & $t$ & $p$ & $95 \%$ & Conf. interval \\
\hline Human & $0.2401^{* *}$ & 0.0755 & 3.18 & $\leq 0.01$ & 0.0914 & 0.3889 \\
\hline City & $7.3946^{* * *}$ & 0.8164 & 9.06 & $\leq 0.001$ & 5.7859 & 9.0033 \\
\hline IND & -0.1016 & 0.0965 & -1.05 & 0.293 & -0.2917 & 0.0885 \\
\hline MES & -0.0668 & 0.0438 & -1.52 & 0.129 & -0.1532 & 0.0196 \\
\hline $\mathrm{R} \& \mathrm{D}(\mathrm{KNO} \leq 6.4457)$ & -154.8469 & 20.9599 & -7.39 & 0.100 & -196.1467 & -113.5470 \\
\hline $\mathrm{R} \& \mathrm{D}(\mathrm{KNO}>6.4457)$ & $11.7948^{* *}$ & 4.6575 & 2.53 & $\leq 0.01$ & 2.6175 & 20.9721 \\
\hline Cons & $10.8113^{* * *}$ & 0.5568 & 19.42 & $\leq 0.001$ & 9.7140 & 11.9085 \\
\hline
\end{tabular}

Notes: ${ }^{*}$ means $p \leq 0.05,{ }^{* *}$ means $p \leq 0.01$, and ${ }^{* * *}$ means $p \leq 0.001$.

\section{Conclusions and Implications}

5.1. Conclusions. The improvement of the regional innovation capability is an important issue that requires deepening supplyside structural reform and promoting high-quality economic development. In this study, based on the economic development stage of "innovation-driven development" and the panel data of 30 regions in China from 2009 to 2018, a nonlinear threshold model of government R\&D investment, knowledge accumulation, and regional innovation capability was constructed, and the complex mechanism of government $\mathrm{R} \& \mathrm{D}$ investments promoting regional innovation capability was clarified by combining the spatial and temporal heterogeneity factors. The theoretical and empirical analysis presented in this paper reveals the following conclusions:
(1) Government R\&D investments have a significant impact on regional innovation capability, and the threshold model with knowledge accumulation level as the threshold variable, government R\&D investment as the core explanatory variable, and regional innovation capability as the explanatory variable passed the significance test, and the estimated threshold value obtained by the likelihood ratio function diagram is consistent with the real threshold value.

(2) The positive influence of government R\&D investments on the promotion of regional innovation capability is limited by the influence of the regional knowledge accumulation level, as government R\&D investments have no significant inhibitory effects on 
the promotion of regional innovation capability in the regions with a low level of knowledge accumulation $(\mathrm{KNO} \leq 6.4457)$, and they have a suddenly changed effect on regional innovation capability in the regions with a high level of knowledge accumulation (KNO > 6.4457), changing from insignificantly negative to significantly positive.

5.2. Policy Implications. According to our conclusions, the following policy recommendations can be made.

First, from the perspective of tax policy, regional governments should issue more effective preferential policies to strengthen the development of high-tech industries and high-knowledge-intensive industries within the region through financial subsidies or tax incentives, thus promoting regional industrial upgrading and optimizing industrial structure. Meanwhile, through setting up a special talent fund, the government can attract highquality talents to settle in the area and start businesses, promoting knowledge spillover and knowledge flow within the region, and deepening the accumulation of regional knowledge.

Second, from the perspective of location difference, for regions with a high level of knowledge accumulation, the government should maintain steady $R \& D$ support to stimulate the innovation vitality of enterprises in the region, making up for the shortage of high-cost innovation activities, guiding enterprises to carry out more effective innovation and $\mathrm{R} \& \mathrm{D}$ activities, and promoting the update of production technology, strengthening the ability for independent innovation, and improving the sustainability of innovation. For the regions with low levels of knowledge accumulation, the government should increase $R \& D$ investments in specific industries according to their economic basis and regional location characteristics, so as to enhance the innovation levels of several industries with a certain foundation, establishing regional dominant industries, and eventually driving the innovation level of other weak industries in the region.

Third, from the perspective of independent innovation, regional governments should also pay attention to strengthening the enterprises' ability to absorb and digest advanced technology, and improve their own innovation level through imitation and innovation. Further, R\&D investment in basic research fields should be strengthened to activate original innovation capacity, to avoid falling into the trap of "introduction-backwardness-reintroductionrebackwardness" technology introduction, and finally to realize greater regional innovation capability.

\section{Data Availability}

The data used to support the findings of this study are included within the article.

\section{Conflicts of Interest}

The author declares that there are no conflicts of interest.

\section{Acknowledgments}

This study was supported by the Heilongjiang Province General Undergraduate Colleges and Universities Youth Innovative Talent Training Program (UNPYSCT-2020075).

\section{References}

[1] H. Zhan, "Promotion of momentum in the domestic economic cycle based on the perspective of resource allocation," The Theory and Practice of Finance and Economics, vol. 42, no. 3, pp. 78-84, 2021.

[2] N. Bairoliya and R. Miller, "Demographic transition, human capital and economic growth in China," Journal of Economic Dynamics and Control, vol. 127, no. 1, p. 104117, 2021.

[3] Q. Jin and T. Yan, "International technology spillover and regional innovation ability-an empirical analysis based on the perspective of intellectual property," Journal of International Trade, vol. 3, pp. 14-25, 2017.

[4] J. Chen, L. Wang, and Y. Li, "Natural resources, urbanization and regional innovation capabilities," Resources Policy, vol. 66, 2020.

[5] S. Tambosi, G. Gomes, and M. Amal, "Organisational learning capability and innovation: study on companies located in regional cluster," International Journal of Innovation Management, vol. 24, 2020.

[6] D. Yang, A. X. Wang, K. Z. Zhou et al., "Environmental strategy, institutional force, and innovation capability: a managerial cognition perspective," Journal of Business Ethics, vol. 159, 2019.

[7] J. R. Bruce, J. D. Figueiredo, and B. S. Silverman, "Public contracting for private innovation: government capabilities, decision rights, and performance outcomes," Strategic Management Journal, vol. 40, 2019.

[8] K. Zhang and L. Huang, "Government innovation preference and regional innovation capability: is the wish to repay the backfired?," Public Finance Research, vol. 4, pp. 66-82, 2020.

[9] Z. Li and S. Yang, "Fiscal decentralization, government innovation preferences and regional innovation efficiency," Management World, vol. 34, no. 12, pp. 29-194, 2018.

[10] P. Xu and S. Huang, "The difference of regional innovation capability in China: from the perspective of government and market," Finance and Economics, vol. 2, pp. 79-91, 2020.

[11] W. Li and M. Zheng, "Is it substantive innovation or strategic innovation? -impact of macroeconomic policies on microenterprises' innovation," Economic Research Journal, vol. 51, no. 4, pp. 60-73, 2016.

[12] J. Chen, "Research on the relationship among government support, enterprise R\&D investment and technological innovation performance," Forecasting, vol. 40, no. 2, pp. 40-46, 2021.

[13] Y. Zhao, X. Han, X. Yang, and Z. Li, "Interorganizational knowledge networks, R\&D alliance networks, and innovation capability: a multilevel network perspective," Complexity, vol. 2021, Article ID 8820059, 22 pages, 2021.

[14] Y. Su and Y.-q. Yu, "Spatial agglomeration of new energy industries on the performance of regional pollution control through spatial econometric analysis," The Science of the Total Environment, vol. 704, Article ID 135261, 2020.

[15] J. Li and J. Xing, "Why is collaborative agglomeration of innovation so important for improving regional innovation capabilities? A perspective based on collaborative agglomeration of industry-university-research institution," Complexity, vol. 2020, Article ID 7049606, 21 pages, 2020. 
[16] L. Zou, X. Z. Cao, and Y. W. Zhu, "Research on regional hightech innovation efficiency and influence factors: evidence from Yangtze river economic belt in China," Complexity, vol. 2021, Article ID 9946098, 22 pages, 2021.

[17] J. Li, H. Ren, C. Zhang, Q. Li, and K. Duan, "Substantive innovation or strategic innovation? research on multiplayer stochastic evolutionary game model and simulation," Complexity, vol. 2020, Article ID 9640412, 22 pages, 2020.

[18] J. V. Blanes and I. Busom, "Participation in R\&D subsidy programs: who gets the money? The case of Spanish manufacturing firms," Ssrn Electronic Journal, vol. 164, 2003.

[19] D. Neicu, P. Teirlinck, and S. Kelchtermans, "Dipping in the policy mix: do R\&D subsidies foster behavioral additionality effects of R\&D tax credits?," Economics of Innovation and New Technology, vol. 25, no. 3, pp. 218-239, 2016.

[20] B. C. Cin, Y. J. Kim, and N. S. Vonortas, "The impact of public R\&D subsidy on small firm productivity: evidence from Korean SMEs," Small Business Economics, vol. 48, 2017.

[21] P. Xu, M. Zhang, and M. Gui, "How R\&D financial subsidies, regional $\mathrm{R} \& \mathrm{D}$ input, and intellectual property protection affect the sustainable patent output of SMEs: evidence from China," Sustainability, vol. 12, 2020.

[22] S. Lach, "Do R\&D subsidies stimulate or displace private $\mathrm{R} \& \mathrm{D}$ ? Evidence from Israel," The Journal of Industrial Economics, vol. 50, 2010.

[23] B. Philipp, "The allocation and effectiveness of China's R\&D subsidies-evidence from listed firms," Research Policy, vol. 45, no. 9, 2016.

[24] A. Pyka, M. Kudic, and M. Mueller, "Systemic interventions in regional innovation systems: entrepreneurship, knowledge accumulation and regional innovation," Regional Studies, vol. 53, 2019.

[25] H. Chen and J. Hou, "Independent R\&D innovation, knowledge accumulation and science-technology performance: the dynamic threshold mechanism based on high-tech industry," Studies in Science of Science, vol. 34, no. 09, pp. 1301-1309+1425, 2016.

[26] B. E. Hansen, "Threshold effects in non-dynamic panels: estimation, testing, and inference," Journal of Econometrics, vol. 93, no. 2, pp. 345-368, 1999.

[27] B. E. Hansen, "Sample splitting and threshold estimation," Econometrica, vol. 68, no. 3, pp. 575-603, 2000.

[28] L. Gerlitz, C. Meyer, C. Meyer et al., "Marketing and branding strategy for the South Baltic Sea Region: reinforcing regional innovation in SMEs through cross-border collaboration models in the age of transformation," Entrepreneurship and Sustainability Issues, vol. 8, 2021.

[29] Y. Su, X. An, X. H. Wang et al., "Impact of innovation human capital investment on innovation performance of regional innovation system based on intellectual property protection intensity threshold regression," Studies in Science of Science, vol. 5, pp. 771-781, 2017.

[30] Y. Su, X. Jiang, and Z. Lin, "Simulation and relationship strength: characteristics of knowledge flows among subjects in a regional innovation system," Science Technology \& Society, vol. 3, 2021.

[31] D. Czarnitzki and A. A. Toole, "Business R\&D and the interplay of R\&D subsidies and product market uncertainty," Review of Industrial Organization, vol. 31, no. 3, pp. 169-181, 2007.

[32] R. J. Barro and J. W. Lee, "A new data set of educational attainment in the world, 1950-2010," Journal of Development Economics, vol. 104, pp. 184-198, 2013.
[33] J. J. Zeng and D. P. Zhou, "Research on the influences of government innovation input and city size on urban innovation capability," Urban Problems, vol. 5, pp. 55-64, 2019.

[34] E. Komlosi and B. Páger, "The impact of urban concentration on countries' competitiveness and entrepreneurial performance," SSRN Electronic Journal, 2015.

[35] J. Zheng, X. Shao, W. Liu, J. Kong, and G. Zuo, "The impact of the pilot Program on industrial structure upgrading in lowcarbon cities," Journal of Cleaner Production, vol. 290, no. 1, Article ID 125868, 2021.

[36] T. Li, D. Han, Y. Ding, and Z. Shi, "How does the development of the internet affect green total factor productivity? Evidence from China," IEEE Access, vol. 8, pp. 216477-216490, 2020.

[37] S. Liu and A. Hu, "Test on the externality of infrastructure in China: 1988-2007," Economic Research Journal, vol. 45, no. 3, pp. $4-15,2010$

[38] S. Qi and Y. Li, "Threshold effects of renewable energy consumption on economic growth under energy transformation," China Population, Resources and Environment, vol. 28, no. 2, pp. 19-27, 2018. 